\title{
The effect of diclofenac sodium on neural tube development in the early stage of chick embryos
}

\author{
T. Ertekin ${ }^{1}$, A. Bilir, E. Aslan², B. Koca ${ }^{3}$, O. Turamanlar ${ }^{1}$, A. Ertekin ${ }^{4}$, S. Albay ${ }^{5}$ \\ ${ }^{1}$ Department of Anatomy, University of Afyon Kocatepe, School of Medicine, Afyonkarahisar, Turkey \\ ${ }^{2}$ Department of Histology and Embryology, University of Afyon Kocatepe, School of Medicine, Afyonkarahisar, Turkey \\ ${ }^{3}$ Department of Biochemistry, University of Afyon Kocatepe, School of Medicine, Afyonkarahisar, Turkey \\ ${ }^{4}$ Emergency Medicine, Afyonkarahisar State Hospital, Afyonkarahisar, Turkey \\ ${ }^{5}$ Department of Anatomy, University of Süleyman Demirel, School of Medicine, Isparta, Turkey
}

[Received: 4 June 2018; Accepted: 9 July 2018]

Background: Neural tube defects are congenital malformations of the central nervous system. Genetic predisposition and some environmental factors play an important role in the development of neural tube defects. This study aimed to investigate the effects of diclofenac sodium on the neural tube development in a chick embryo model that corresponds to the first month of vertebral development in mammals.

Materials and methods: Seventy-five fertile, specific pathogen-free eggs were incubated for $28 \mathrm{~h}$ and were divided into five groups of 15 eggs each. Diclofenac sodium was administered via the sub-blastodermic route at this stage. Incubation was continued till the end of the $48^{\text {th }} \mathrm{h}$. All eggs were then opened and embryos were dissected from embryonic membranes and evaluated morphologically and histopathologically.

Results: It was determined that the use of increasing doses of diclofenac sodium led to defects of midline closure in early chicken embryos. There were statistically significant differences in neural tube positions (open or close) among the groups. In addition; crown-rump length, somite number were significantly decreased in high dose experimental groups compared with control group.

Conclusions: This study showed that development of neurons is affected in chicken embryos after administration of diclofenac sodium. The exact teratogenic mechanism of diclofenac sodium is not clear; therefore it should be investigated. (Folia Morphol 2019; 78, 2: 307-313)

Key words: diclofenac sodium, chick embryo, neural tube defect, development

\section{INTRODUCTION}

Non-steroidal anti-inflammatory drugs (NSAIDs) are important chemicals in the human body and have been widely used for alleviation of pain, inflammation, myocardial infarction and stroke [22]. NSAIDs have different side effects, such as gastrointestinal damage, platelet dysfunction and convulsions when co-administered with quinolone-derivative antibacterial drugs $[11,36,42]$. Diclofenac sodium (sodium-(O((2,6-dichlorophenyl)-amino)-phenyl)-acetate) (DS) is a NSAID characterised by a relatively low molecular weight, having potent anti-inflammatory, analgesic, and antipyretic effects on tissues $[35,37]$ and used commonly by women of reproductive age for treat-

Address for correspondence: T. Ertekin, PhD, Associate Professor, Department of Anatomy, University of Afyon Kocatepe, School of Medicine, Afyonkarahisar, Turkey, tel: 0090505 6482854, fax: 0090027224633 00, e-mail: tolga.ertekin@yahoo.com.tr 
ment of dysmenorrhoea and menorrhagia [12]. Up to $20 \%$ of women consume prescribed medicine during the first trimester of pregnancy; of these medications, $3 \%$ are NSAIDs [28]. DS acts by inhibiting the enzyme cyclooxygenase (COX), reducing the arachidonic acid release and enhancing its uptake. The COX reaction is the rate-limiting step in the formation of prostaglandins from arachidonic acid. COX-2, the inducible isoform of COX family, is selectively expressed in neurons of the cerebral cortex, hippocampus, and amygdale. Prostaglandins are important chemical mediators in the human body, being involved in both normal and abnormal function of virtually every organ and system $[2,37]$.

It was determined that DS crosses from the human placenta during the first and second trimesters to foetus [30,37]. The fact that DS cross the placental barrier to prevent the biosynthesis of prostanoids and passes into the foetal circulation causes important side effects and sometimes malformations in newborns $[12,29,45]$. Some assays determined that the DS using throughout the perinatal period may cause teratogenic effects on some organs $[3,6,16,19]$. In addition; the use of DS during embryonic development of the central nervous system (CNS) can produce a wide array of neurological dysfunctions and neuroanatomical anomalies in animal models [9, 22]. However, very little information is available respecting DS effects on neurological structures especially with regard to prenatal development.

Congenital CNS anomalies are the second most prevalent anomalies following congenital cardiovascular anomalies [24]. Neural tube defects (NTD) are an important area of congenital malformations. Genetic predisposition and some environmental factors play a significant role in the development of NTDs. NTDs, which occur in approximately 6/10000 newborns, create a heterogeneous and complex group of congenital anomalies [43].

Neuronal and spinal development stages of chick embryo are closely similar to the development stages of human embryos. To the best of our knowledge, there was no study in the literature that investigates the toxic effects of DS on neural tube (NT) development by using chick embryo model. This study was designed to fill this gap in knowledge and to determine the probable toxic effect of DS with respect to different doses. Thereby, it was also aimed to determine potential results with its use during pregnancy.

\section{MATERIALS AND METHODS}

This study was conducted in Afyon Kocatepe University, Department of Anatomy Laboratory. All the experiments were performed following ethical guidelines established for animal usage by Institutional Animal Ethics Committee (IAEC) Afyon Kocatepe University. The 75 eggs were procured from the Veterinarian Control and Research Institute, Bornova, Izmir, Turkey, $65 \pm 5 \mathrm{~g}$ in weight, specific pathogen-free and day 0 fertilised eggs of white chickens. The eggs were placed in the incubator with sharp ends pointing down in order to ensure the continuity of the embryos and to have them available at the times desired. The incubator was kept at a constant temperature range of $37.8 \pm 0.2^{\circ} \mathrm{C}$ and humidity of $60-70 \%$. The eggs were automatically rolled every $2 \mathrm{~h}$ at a $45^{\circ}$ angle to the vertical axis during the incubation period.

The eggs were opened using window procedure after 28-h incubation (the embryos reached stage 8 of development according to Hamburger and Hamilton), and were divided into five groups of 15 eggs each (with one control and four experimental groups) [20]. Firstly; the egg shell was sterilised with povidone-iodine (10\%) and then ethanol (70\%). A small window $(1-2 \mathrm{~cm})$ was made aseptically with a specific technique in the eggshell. The round-shaped embryonic disc became visible after the surrounding membranes were cut. At this stage; under sterile conditions, DS (Voltaren, $75 \mathrm{mg} / 3 \mathrm{~mL}$ ampoule, Novartis, Kartal, Istanbul, Turkey) was diluted in saline and prepared in the selected dosages. In humans; the recommended daily dose is $50 \mathrm{mg} /$ day. The daily dose can be increased to a total of $200 \mathrm{mg} /$ day according to the severity of the symptoms. The maximum daily dose is $200 \mathrm{mg} /$ day $[14,41]$. For animals, $1-18 \mathrm{mg} / \mathrm{kg}$ DS doses were used in teratogenic studies related to pregnancy $[3,6,19,44]$. A toxic dose of DS was $5 \mathrm{mg} / \mathrm{kg}$ in avian species [1, 33]. Four doses were tested: first dose, $1 / 20$ of the toxic dose $=0.25 \mathrm{mg} / \mathrm{kg}$; second dose, $1 / 10$ of the toxic dose $=0.5 \mathrm{mg} / \mathrm{kg}$; third dose, $1 / 5$ of the toxic dose $=1 \mathrm{mg} / \mathrm{kg}$; and fourth dose, $1 / 2.5$ of the toxic dose $=2 \mathrm{mg} / \mathrm{kg}$.

Diclofenac sodium was administered via the subblastodermic route in a volume of $10 \mu \mathrm{L}$ in groups $\mathrm{B}, \mathrm{C}, \mathrm{D}$ and $\mathrm{E}$ by Hamilton microinjector $(0.25 \mathrm{mg} / \mathrm{kg}$, $0.5 \mathrm{mg} / \mathrm{kg}, 1 \mathrm{mg} / \mathrm{kg}$ and $2 \mathrm{mg} / \mathrm{kg}$ in groups B, C, D and E, respectively). Group $A$ served as the control group and was administered $10 \mu \mathrm{L} 0.9 \% \mathrm{NaCl}$ via the subblastodermic route. After treatment, small window was sealed with cellophane tape. Then the eggs were 


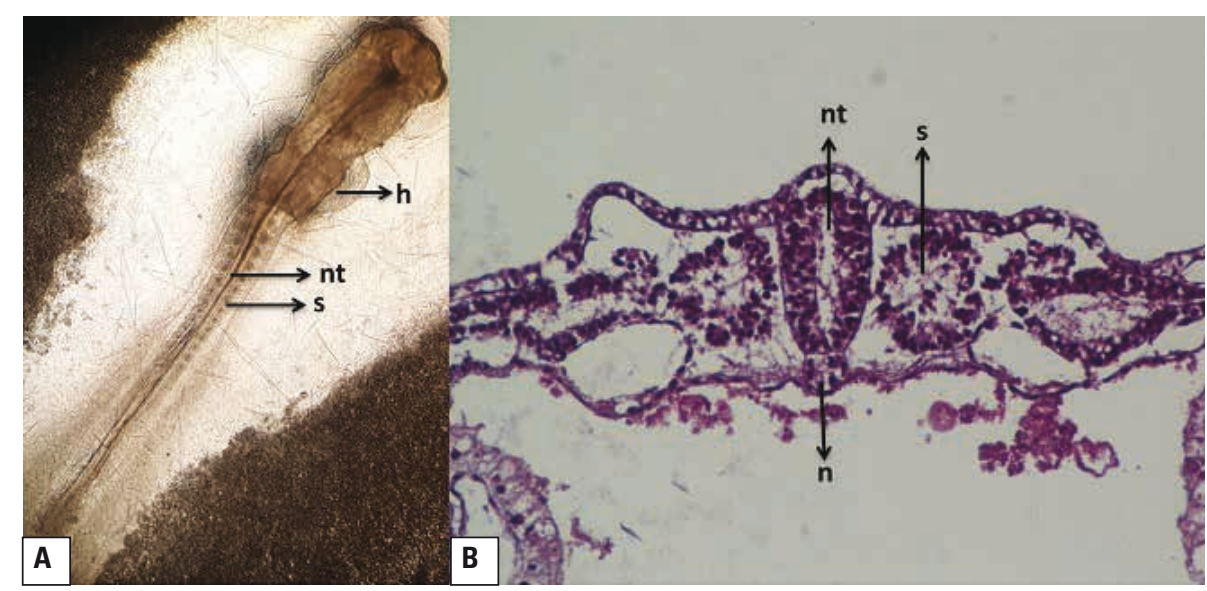

Figure 1. A. Normal appearance of post-incubation 2-day chick embryo of group A; B. Histopathologic views of normal chicken embryos under light microscope $(H \& E, \times 20)$; nt - neural tube; $n$ - notochord; s - somites; $h$ - heart.

hand-turned $180^{\circ}$ and placed in the incubator. All eggs were opened at the $48^{\text {th }} \mathrm{h}$ (Hamburger-Hamilton stage 12), and the morphological features of each embryo were evaluated under stereomicroscope to assess any gross developmental abnormalities [20]. Embryos were classified as with defect, normal or undeveloped. The samples were then transferred to Petri dishes containing 10\% formaldehyde solutions for histopathological study. The embryos from each group were fixed in $10 \%$ formaldehyde, dehydrated through a graded alcohol series, cleaned in xylene and then embedded in paraffin wax. Serial sections of four micron thickness were taken from the paraffin blocks and stained with haematoxylin and eosin (H\&E) dye. The sections were examined using a light microscope.

\section{Statistical analysis}

Analysis of all findings was performed using the Statistical Package for the Social Sciences (SPSS) 22.0 programme. The data related to NT (open or closed) were analysed by using $\chi^{2}$ test. The somite number, crown-rump length and protein contents were analysed by using non-parametric Kruskal-Wallis tests. Dunn test were employed as post-hoc tests and $p<0.001$ were considered significant.

\section{RESULTS}

In our study, we investigated the effect of DS at different dosages on NT development.

Group A: 15 embryos (100\%) in group A were expected to be according to Hamburger-Hamilton embryonic classification stage 12 and their NTs were closed. No malformation or developmental retardation was observed. The tissue samples observed under the light microscope after staining with H\&E were found to be consistent with the stereomicroscopic examination (Fig. 1).

Group B: 7 embryos (46.7\%) had NTD and 8 embryos (53.3\%) were intact and these embryos sustained their normal development and were in the embryonic stage 12 where they were expected to be according to Hamburger-Hamilton classification (Fig. 2).

Group C: 8 embryos (53.3\%) had NTD, 7 embryos (46.7\%) were intact and their NTs were closed (Fig. 3).

Group D: 13 embryos had NTD (86\%) and 2 embryos (14\%) were intact and their NTs were closed.

Group E: 15 embryos (100\%) had NTD and 1 of these embryos was undeveloped and its development stage was 9 according to Hamburger-Hamilton embryonic classification (Fig. 4).

There were statistically significant differences ( $p<0.001$ ) in NT positions (open or close) among the groups. The crown-rump length and mean somite numbers were diminished in experimental groups according to used dosages compared to control group. These decreases were determined statistically significant $(p<0.001$, Table 1$)$.

\section{DISCUSSION}

Neural tube defects are serious birth defects of the CNS that occur during embryonic development when the NT fails to close completely, leading to brain and spine anomalies that can lead to death or lifelong disability [5]. The period from appearance of neural plaque up to closure of palate, i.e. the period between $18^{\text {th }}$ day and $60^{\text {th }}$ day of pregnancy, is the period where the possibility of congenital anomaly is highest, often before women are aware 


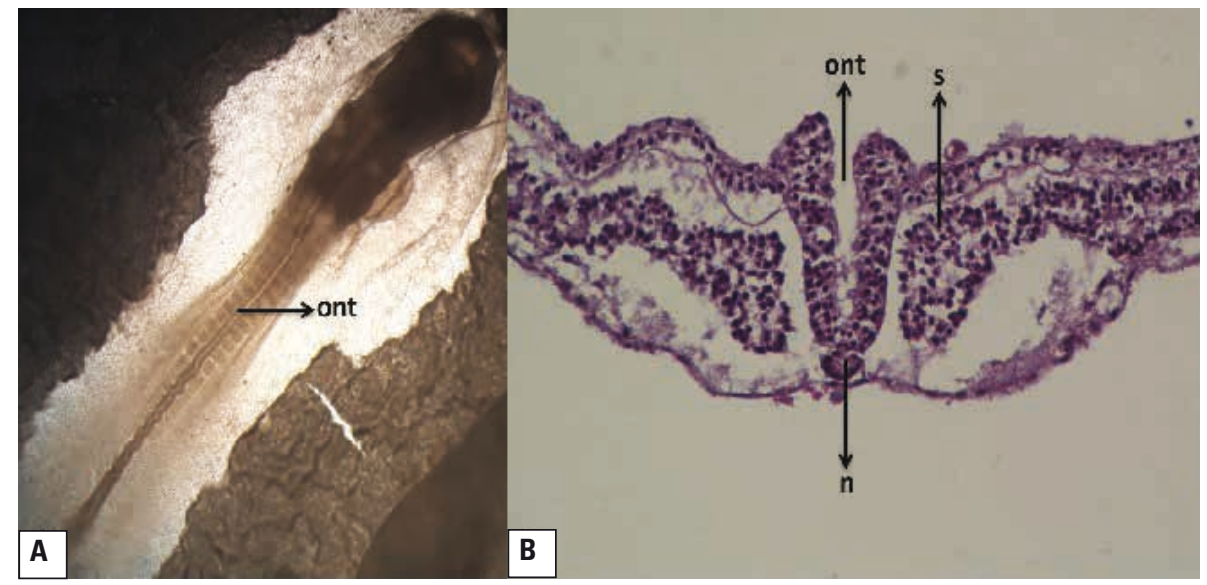

Figure 2. A. The opening in the neural tube is seen in the light microscope view of group B; B. A histologic section was obtained and stained with $\mathrm{H} \& \mathrm{E}$. The neural tube is open in the light microscope image of the same group $(\mathrm{H} \& \mathrm{E}, \times 20)$; ont - open neural tube; $\mathrm{n}-$ notochord; $\mathrm{s}$ - somites; $\mathrm{h}$ - heart.

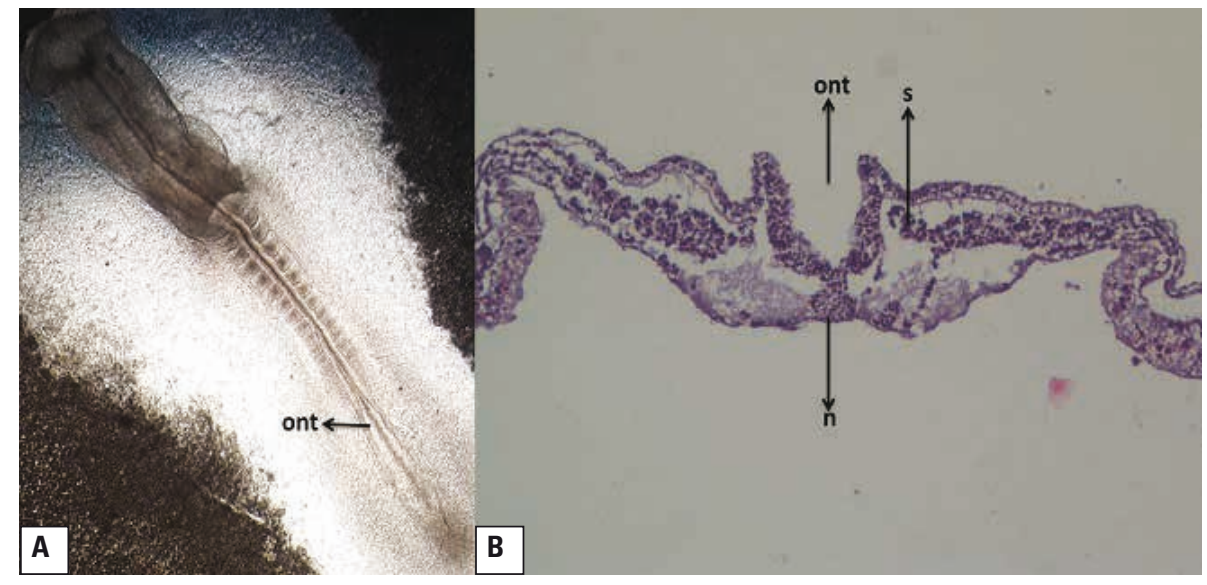

Figure 3. A. The neural tube is not closed in the light microscope image of the group C; B. A histologic section was obtained and stained with $\mathrm{H} \& \mathrm{E}$. The neural tube is open in the light microscope image of the same group $(\mathrm{H} \& \mathrm{E}, \times 20)$; ont — open neural tube; $\mathrm{n}$ - notochord; $s$ - somites; $h$ - heart.

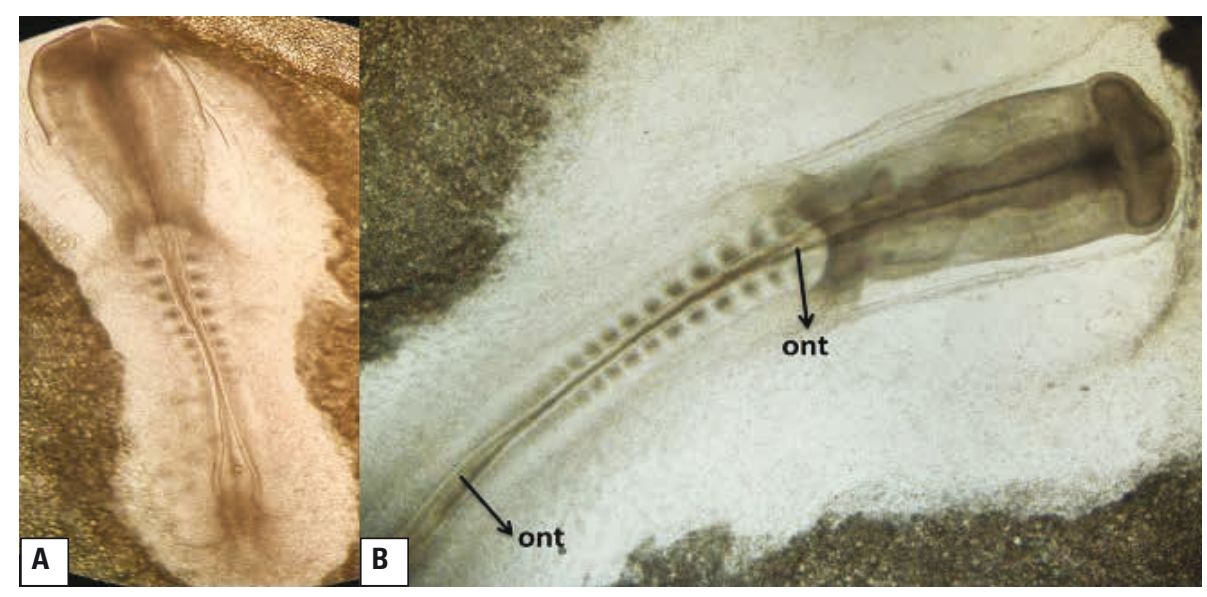

Figure 4. A. Developmental retardation seen in the light microscope view of group E; B. The opening in the neural tube is seen in the cervical and caudal region of the chick embryo of group $\mathrm{E}$; ont — open neural tube. 
Table 1. The statistical analyses embryonic development in control and experimental groups (with diclofenac sodium)

\begin{tabular}{lcccccc}
\hline Parameters & Group A & Group B & Group C & Group D & Group E & P \\
\hline Open NT/Close NT & $0 / 15$ & $7 / 8$ & $8 / 7$ & $13 / 2$ & $15 / 0$ & $<0.001^{*}$ \\
Crown-rump length $[\mu \mathrm{m}]$ & $639.06 \pm 105.48$ & $559.42 \pm 118.61$ & $540.02 \pm 113.86$ & $498.02 \pm 83.94$ & $497.62 \pm 76.52$ & $<0.001^{* *}, \#$ \\
Somite number & $17.73 \pm 1.98$ & $14.73 \pm 3.03$ & $14.60 \pm 3.73$ & $12.86 \pm 3.22$ & $12.86 \pm 2.55$ & $<0.001^{* *}, \#$ \\
\hline
\end{tabular}

${ }^{*}$ Chi-square test; ${ }^{* *}$ Kruskal-Wallis test; ${ }^{\#}$ The difference was determined between group A and group D, group A and group E; NT — neural tube

they are pregnant. These anomalies originate from insufficiency in NT formation or re-opening after formation of NT [15, 40]. Genetic and environmental factors (geographical factors, socio-economic factors, alcohol and drug use) can be specified in aetiology of NT closure defects [21, 26, 38].

The primary experimental methods of NTD include amphibian, mammalian, poultry, and computer modelling. These models have advantages and disadvantages compared to each other. The early chick embryo model that corresponds to the first month of embryonal development in mammals is an ideal modelling [13].

In addition, the studies have demonstrated that cytochalasins, papaverine, diazepam, caffeine, ethanol, folic acid antagonists such as methotrexate and aminopterin, antiepileptic drugs such as phenytoin and lacosamide, and local anaesthetics cause NT closure defects in early stage chick embryos $[4,18,23,25,39]$.

It is known that NSAIDs are one of the commonest drugs prescribed by general practitioners worldwide, and they have been taken during the early conception period [37]. DS may trigger alterations in the CNS morphology having long-term teratogenic effects on neuronal development [10]. The developing CNS is also the most vulnerable to insufficient and harmful conditions such as drug exposure during the gestational stage [17]; since different parts of the CNS form at different stages of development, there is not one critical period but many critical periods. Some neurons are formed around the time of closure of the NT [34].

In this study, possible adverse effect of DS on the NT was investigated in chick embryo model. All embryos in the control group that were monitored under the microscope after $48 \mathrm{~h}$ had reached the appropriate embryonic stage according to the Hamburger-Hamilton method. The effects of DS on the embryo were correlated with the dose of DS. It was determined that the use of increasing doses of DS led to defects of midline closure in early chicken em- bryos. All embryos had NTD in the high dose group. In addition; crown-rump length, somite number were significantly decreased in high dose experimental groups (groups C, D) compared with control group.

Assays related to DS have reported that its teratogenic effect risk is low in case it is used in pregnancy, but they are limited. However, the mechanism of embryonic damage related to DS use is uncertain $[6,9]$.

Researchers showed that diclofenac inhibited implantation and embryonic development in rats when given on gestation day 5 . In this study, rat blastocysts were cultured in diclofenac in vitro, then implanted to host mothers on day 5 of pseudopregnancy. Large doses of diclofenac $(75 \mu \mathrm{g} / \mathrm{mL})$ in culture were toxic. Smaller doses $(40 \mu \mathrm{g} / \mathrm{mL})$ had a profound effect on implantation. Another group of host mothers received diclofenac i.p., $1 \mathrm{~h}$ prior to transfer of untreated blastocysts. Control animals had a $72 \%$ implantation rate, whereas there was only a $35-41 \%$ implantation rate after in vitro diclofenac treatment. They determined that prostaglandin appears to be essential during the process of implantation and placentation. When this process is disturbed by DS the number of growthretarded embryos increases. If DS is such a potent inhibitor of prostaglandin synthetase it should be expected that decidualisation would also be defective. In the treated host mothers only $7 \%$ of embryos were normal, while $34 \%$ were growth-retarded [7]. Similar to above study; another assay was reported a positive correlation between use of NSAID during pregnancy and miscarriages [27].

The effect of DS on the developing embryo during the critical period of organogenesis was investigated by using a whole rat embryo culture model. They exposed to embryos various concentrations of DS and scored for growth and differentiation at the end of the culture period. It was found that although caudal NT, flexion and hind limb were significantly lower in embryos exposed high concentration of DS (7.5 and $15.0 \mu \mathrm{g} / \mathrm{mL}$ ); there were no effect low doses of 
it. Based on their results it was suggested that high concentration of DS has a teratogenic effect [9]. Same researchers thought that the teratogenic effects of NSAIDs might be mediated through free oxygen radical production. The influence of DS on cellular reactive oxygen species production in embryos was evaluated by measuring 8 isoprostaglandin $F 2 \alpha$ level. Their results showed that 8-isoprostaglandin $\mathrm{F} 2 \alpha$ level was significantly elevated in embryos exposed to high concentration of DS (7.5 and $15.0 \mu \mathrm{g} / \mathrm{mL}$ ) but no significant difference was detected between the control and low concentration group $(1.5 \mu \mathrm{g} / \mathrm{mL})$. Embryos exposed to the high concentration of DS $(15.0 \mu \mathrm{g} /$ $/ \mathrm{mL}$ ) had a significantly lower total morphology scores for caudal NT, hind limb, flexion, and brain. There was no significant difference in yolk sac diameter, crown-rump length or number of somite between experimental and control groups [8]. Free oxygen radicals are highly reactive and unstable. In the event of oxidative stress, free radicals are in excess, resulting in cellular damage. Embryotoxic effects of reactive oxygen species may be related to oxidative damage to DNA and other cellular macromolecules [31].

Prenatally exposed DS had a neurotoxicity effect in the CNS, namely the pyramidal and granular cells of hippocampus [17] and Purkinje cells of cerebellum [32]. NSAIDs suppress cell proliferation in the spinal cord and dorsal root ganglia by affecting cell cycle regulators since it has been shown that DS, in contrast to other NSAIDs including aspirin, naproxen, indomethacin and ibuprofen, restrains the differentiation of neuronal stem cells into neurons and also suppresses cell proliferation via the induction of apoptosis. Therefore, DS appears to have some negative effect on both development and differentiation nerve cells $[2,22]$.

\section{CONCLUSIONS}

Consequently, our study has demonstrated that DS exerts direct teratogenic effect on the process of NT formation of chick embryo in a dose-dependent manner. It has also been shown that DS significantly decreases the crown-rump length and somite number in high dose experimental groups compared with control group. The chosen model does not directly reflect the environment and conditions of a developing human embryo. Therefore, it is not possible to simply extend and apply the results observed in chick embryos to humans. However, the chick embryo model has the advantage of allowing the investiga- tion of potentially hazardous substances directly on the embryo. In the present study, we did not use specific markers of neurons to see the toxicity induced by diclofenac. We interpreted our results based on the light of histopathological findings. It is clear that improved technical materials and studies with larger sample sizes would be useful to confirm the toxic effects of DS in prenatal period. Further investigation on the exact mechanism of diclofenac toxicity would be valuable. Present findings cannot serve as definitive evidence of the use of DS for embryo-toxicity but it does provide an experimental basis for the caution of DS use prescription in pregnancy.

\section{REFERENCES}

1. Akter $R$, Sarker M. Effect of diclofenac sodium in broilers. Bangl J Vet Med. 2015; 13(1): 19-24, doi: 10.3329/bjvm. v13i1.23710.

2. Andreasson KI, Savonenko A, Vidensky S, et al. Age-dependent cognitive deficits and neuronal apoptosis in cyclooxygenase-2 transgenic mice. J Neurosci. 2001; 21(20): 8198-8209, indexed in Pubmed: 11588192.

3. Arslan $\mathrm{H}$, Aktaş A, Elibol E, et al. Effects of prenatal diclofenac sodium exposure on newborn testis: a histomorphometric study. Biotech Histochem. 2016; 91(4): 277-282, doi: 10.310 9/10520295.2016.1151551, indexed in Pubmed: 26984645.

4. Barutcuoglu M, Selcuki M, Vatansever S, et al. The effects of ethanol on neural tube development in early stage neural tube development chick embryos. Türk Nöroşir Derg. 2001; 11: 32-36.

5. Botto LD, Moore CA, Khoury MJ, et al. Neural-tube defects. N Engl J Med. 1999; 341(20): 1509-1519, doi: 10.1056/ NEJM199911113412006, indexed in Pubmed: 10559453.

6. Canan S, Aktaş A, Ulkay MB, et al. Prenatal exposure to a non-steroidal anti-inflammatory drug or saline solution impairs sciatic nerve morphology: a stereological and histological study. Int J Dev Neurosci. 2008; 26(7): 733-738, doi: 10.1016/j.ijdevneu.2008.07.005, indexed in Pubmed: 18678241.

7. Carp HJ, Fein A, Nebel L. Effect of diclofenac on implantation and embryonic development in the rat. Eur J Obstet Gynecol Reprod Biol. 1988; 28(3): 273-277, indexed in Pubmed: 3208969.

8. Chan LYS, Chiu PYu, Siu NSS, et al. Diclofenac-induced embryotoxicity is associated with increased embryonic 8-isoprostaglandin F2alpha level in rat whole embryo culture. Reprod Toxicol. 2002; 16(6): 841-844, indexed in Pubmed: 12401513.

9. Chan LY, Chiu PY, Siu SS, et al. A study of diclofenac-induced teratogenicity during organogenesis using a whole rat embryo culture model. Hum Reprod. 2001; 16(11): 2390-2393, indexed in Pubmed: 11679526.

10. Chen LC, Ashcroft DM. Do selective COX-2 inhibitors increase the risk of cerebrovascular events? A meta-analysis of randomized controlled trials. J Clin Pharm Ther. 2006; 31(6): 565-576, doi: 10.1111/j.1365-2710.2006.00774.x, indexed in Pubmed: 17176361.

11. Davey PG. Overview of drug interactions with the quinolones. J Antimicrob Chemother. 1988; 22 Suppl C: 97-107, indexed in Pubmed: 3053579.

12. Dawood MY. Nonsteroidal antiinflammatory drugs and reproduction. Am J Obstet Gynecol. 1993; 169(5): 1255-1265, doi: 10.1016/0002-9378(93)90292-q. 
13. Drake VJ, Koprowski SL, Lough JW, et al. Gastrulating chick embryo as a model for evaluating teratogenicity: a comparison of three approaches. Birth Defects Res A Clin Mol Teratol. 2006; 76(1): 66-71, doi: 10.1002/bdra.20202, indexed in Pubmed: 16333841 .

14. Fortun PJ, Hawkey CJ, Fortun PJ, et al. Nonsteroidal antiinflammatory drugs and the small intestine. Curr Opin Gastroenterol. 2005; 21(2): 169-175, indexed in Pubmed: 15711208.

15. Gardner WJ. Myelomeningocele, the result of rupture of the embryonic neural tube. Cleve Clin Q. 1960; 27: 88-100, indexed in Pubmed: 13826548.

16. Gevrek F, Kara M, Ragbetli M, et al. Effects of prenatally exposed diclofenac sodium on rat heart tissue:a stereological and histological study. Turk J Med Sci. 2015; 45: 474-480, doi: 10.3906/sag-1404-173.

17. Gokcimen A, Rağbetli MC, Baş O, et al. Effect of prenatal exposure to an anti-inflammatory drug on neuron number in cornu ammonis and dentate gyrus of the rat hippocampus: a stereological study. Brain Res. 2007; 1127(1): 185-192, doi: 10.1016/j.brainres.2006.10.026, indexed in Pubmed: 17123485.

18. Güney $\mathrm{O}$, Canbilen A, Konak A, et al. The effects of folic acid in the prevention of neural tube development defects caused by phenytoin in early chick embryos. Spine (Phila Pa 1976). 2003; 28(5): 442-445, doi: 10.1097/01. BRS.0000048647.17577.13, indexed in Pubmed: 12616154.

19. Güven D, Altunkaynak BZ, Ayranci E, et al. Stereological and histopathological evaluation of ovary and uterine horns of female rats prenatally exposed to diclofenac sodium. J Obstet Gynaecol. 2013; 33(3): 258-263, doi: 10.3109/01443615.2 012.761185, indexed in Pubmed: 23550853.

20. Hamburger $\mathrm{V}$, Hamilton $\mathrm{HL}$. A series of normal stages in the development of the chick embryo. J Morphol. 1951; 88(1): 49-92, indexed in Pubmed: 24539719.

21. Honein MA, Paulozzi $\sqcup$, Mathews TJ, et al. Impact of folic acid fortification of the US food supply on the occurrence of neural tube defects. JAMA. 2001; 285(23): 2981-2986, indexed in Pubmed: 11410096.

22. Kudo C, Kori M, Matsuzaki K, et al. Diclofenac inhibits proliferation and differentiation of neural stem cells. Biochem Pharmacol. 2003; 66(2): 289-295, indexed in Pubmed: 12826271.

23. Lee H, Nagele RG, Pietrolungo JF. Toxic and teratologic effects of caffeine on explanted early chick embryos. Teratology. 1982; 25(1): 19-25, doi: 10.1002/tera.1420250104, indexed in Pubmed: 7064111.

24. Manning N, Archer N. Treatment and outcome of serious structural congenital heart disease. Semin Neonatol. 2001; 6(1): 37-47, doi: 10.1053/siny.2000.0033, indexed in Pubmed: 11162284 .

25. Mete M, Gurcu B, Collu F, et al. Effects of lacosamide "a novel antiepileptic drug" in the early stages of chicken embryo development. Childs Nerv Syst. 2016; 32(9): 1715-1719, doi: 10.1007/s00381-016-3181-4, indexed in Pubmed: 27473858.

26. Mortimer EA. The puzzling epidemiology of neural tube defects. Pediatrics. 1980; 65(3): 636-638, indexed in Pubmed: 7360557.

27. Nielsen GL, Sørensen HT, Larsen $H$, et al. Risk of adverse birth outcome and miscarriage in pregnant users of non-steroidal anti-inflammatory drugs: population based observational study and case-control study. BMJ. 2001; 322(7281): 266-270, indexed in Pubmed: 11157526.

28. Olesen C, Steffensen FH, Nielsen GL, et al. Drug use in first pregnancy and lactation: a population-based survey among Danish women. The EUROMAP group. Eur J Clin Pharmacol. 1999; 55(2): 139-144, indexed in Pubmed: 10335909.

29. Ostensen M, Ramsey-Goldman R. Treatment of inflammatory rheumatic disorders in pregnancy: what are the safest treatment options? Drug Saf. 1998; 19(5): 389-410, doi: 10.2165/00002018-199819050-00006, indexed in Pubmed: 9825952.

30. Ostensen M. Nonsteroidal anti-inflammatory drugs during pregnancy. Scand J Rheumatol Suppl. 1998; 107: 128-132, indexed in Pubmed: 9759151.

31. Parman T, Chen G, Wells PG. Free radical intermediates of phenytoin and related teratogens. Prostaglandin $\mathrm{H}$ synthase-catalyzed bioactivation, electron paramagnetic resonance spectrometry, and photochemical product analysis. J Biol Chem. 1998; 273(39): 25079-25088, indexed in Pubmed: 9737965.

32. Ragbetli MC, Ozyurt B, Aslan $\mathrm{H}$, et al. Effect of prenatal exposure to diclofenac sodium on Purkinje cell numbers in rat cerebellum: a stereological study. Brain Res. 2007; 1174: 130-135, doi: 10.1016/j.brainres.2007.08.025, indexed in Pubmed: 17868656.

33. Reddy NC, Anjaneyulu Y, Sivasankari B, et al. Comparative toxicity studies in birds using nimesulide and diclofenac sodium. Environ Toxicol Pharmacol. 2006; 22(2): 142-147, doi: 10.1016/j.etap.2006.02.004, indexed in Pubmed: 21783701

34. Rodier PM. Chronology of neuron development: animal studies and their clinical implications. Dev Med Child Neurol. 1980; 22(4): 525-545, indexed in Pubmed: 7409345.

35. Savaşer A, Ozkan Y, Işimer A. Preparation and in vitro evaluation of sustained release tablet formulations of diclofenac sodium. Farmaco. 2005; 60(2): 171-177, doi: 10.1016/j. farmac. 2004.10.001, indexed in Pubmed: 15752476.

36. Segev S, Rehavi M, Rubinstein E. Quinolones, theophylline, and diclofenac interactions with the gamma-aminobutyric acid receptor. Antimicrob Agents Chemother. 1988; 32(11): 1624-1626, indexed in Pubmed: 2855295.

37. Siu SS, Yeung JH, Lau TK. A study on placental transfer of diclofenac in first trimester of human pregnancy. Hum Reprod. 2000; 15(11): 2423-2425, indexed in Pubmed: 11056146.

38. Tunçbilek E, Boduroğlu K, Alikaşifoğlu M. Neural tube defects in Turkey: prevalence, distribution and risk factors. Turk J Pediatr. 1999; 41(3): 299-305, indexed in Pubmed: 10770089.

39. Vatansever HS, Umur AS, Inan VS, et al. The effects of methotrexate on the development of neural tube defects in the chick embryo. Turk J Vet Anim Sci. 2003; 27: 1119-1125.

40. Von Recklinghausen F. Untersuchungen über die Spina bifida. Arch Pathol Anat. 1886; 105: 243-373, doi: 10.1515/9783111485584.

41. Wallace JL, Del Soldato P. The therapeutic potential of NO-NSAIDs. Fundam Clin Pharmacol. 2003; 17(1): 11-20, indexed in Pubmed: 12588626.

42. Yakushiji T, Shirasaki T, Akaike N. Non-competitive inhibition of GABAA responses by a new class of quinolones and non-steroidal anti-inflammatories in dissociated frog sensory neurones. Br J Pharmacol. 1992; 105(1): 13-18, indexed in Pubmed: 1317734.

43. Yerby MS. Clinical care of pregnant women with epilepsy: neural tube defects and folic acid supplementation. Epilepsia. 2003; 44 Suppl 3: 33-40, indexed in Pubmed: 12790884.

44. Yurt KK, Kaplan S, Kivrak EG. The neuroprotective effect of melatonin on the hippocampus exposed to diclofenac sodium during the prenatal period. J Chem Neuroanat. 2018; 87: 37-48, doi: 10.1016/j.jchemneu.2017.05.006, indexed in Pubmed: 28576559.

45. Zenker M, Klinge J, Krüger C, et al. Severe pulmonary hypertension in a neonate caused by premature closure of the ductus arteriosus following maternal treatment with diclofenac: a case report. J Perinat Med. 1998; 26(3): 231-234, indexed in Pubmed: 9773385. 